\title{
Role of CRISPR-Cas system on antibiotic resistance patterns of Enterococcus faecalis
}

\author{
Pourya Gholizadeh 1,2, Mohammad Aghazadeh³, Reza Ghotaslou ${ }^{3}$, Mohammad Ahangarzadeh Rezaee $^{3}$, \\ Tahereh Pirzadeh ${ }^{3}$, Longzhu Cui ${ }^{4}$, Shinya Watanabe ${ }^{4}$, Hadi Feizi ${ }^{1,2}$, Hiva Kadkhoda ${ }^{1,2}$ and Hossein Samadi Kafil ${ }^{* *}$
}

\begin{abstract}
Clustered regularly interspaced short palindromic repeat (CRISPR)-Cas systems are one of the factors which can contribute to limiting the development and evolution of antibiotic resistance in bacteria. There are three genomic loci of CRISPR-Cas in Enterococcus faecalis. In this study, we aimed to assess correlation of the CRISPR-Cas system distribution with the acquisition of antibiotic resistance among E. faecalis isolates. A total of 151 isolates of E. faecalis were collected from urinary tract infections (UTI) and dental-root canal (DRC). All isolates were screened for phenotypic antibiotic resistance. In addition, antibiotic resistance genes and CRISPR loci were screened by using polymerase chain reaction. Genomic background of the isolates was identified by random amplified polymorphic DNA (RAPD)-PCR. The number of multidrug-resistant $E$. faecalis strains were higher in UTI isolates than in DRC isolates. RAPD-PCR confirmed that genomic background was diverse in UTI and DRC isolates used in this study. CRISPR loci were highly accumulated in gentamycin-, teicoplanin-, erythromycin-, and tetracycline-susceptible strains. In concordance with drug susceptibility, smaller number of CRISPR loci were identified in vanA, tetM, ermB, aac6'-aph(2"), aadE, and ant(6) positive strains. These data indicate a negative correlation between CRISPR-cas loci and antibiotic resistance, as well as, carriage of antibiotic resistant genes in both of UTI and DRC isolates.
\end{abstract}

Keywords: Enterococcus faecalis, CRISPR-cas system, Antibiotic resistance, Multi-drug resistance

\section{Introduction}

Over the past decades, commensal bacteria and opportunistic pathogens including Enterococcus spp. have been considered as serious public health threats, and the therapeutic options have become limited. Enterococcus spp. are gram-positive, facultative anaerobes, catalasenegative cocci, which are found in a variety environments such as nature, water, soil, food, avian, mammalian, and human gastrointestinal tracts [1]. The important species within the genus Enterococcus are E. faecalis and E. faecium, which have been reported to be opportunistic pathogens for up to $90 \%$ of human enterococcal infections

\footnotetext{
*Correspondence: Kafilhs@tbzmed.ac.ir

1 Drug Applied Research Center, Tabriz University of Medical Sciences, Tabriz, Iran

Full list of author information is available at the end of the article
}

[2]. Clinical studies demonstrated that E. faecalis are frequently isolated from community- and nosocomialacquired infections such as bacteremia, urinary tract infections (UTIs), endocarditis and soft tissue infections $[2,3]$, as well as from untreated and previously treated root canals infections $[4,5]$. Antibiotic resistance in enterococci is a challenge in the clinical setting, and reduces the efficacy of treatment of Enterococcal infectious diseases [6]. E. faecalis expresses an intrinsic resistance to several antibiotic groups and biocides, including betalactams, glycopeptides, fluoroquinolones, as well as highlevel resistance to aminoglycosides including gentamicin and streptomycin [7]. In addition, enterococci can transfer antibiotic resistance to other bacteria through mobile genetic elements such as transposons and plasmids [6]. Owing to highly efficient mechanisms of enterococci for the distribution and acquisition of antibiotic resistance original author(s) and the source, provide a link to the Creative Commons licence, and indicate if changes were made. The images or other third party material in this article are included in the article's Creative Commons licence, unless indicated otherwise in a credit line to the material. If material is not included in the article's Creative Commons licence and your intended use is not permitted by statutory regulation or exceeds the permitted use, you will need to obtain permission directly from the copyright holder. To view a copy of this licence, visit http://creativecommons.org/licenses/by/4.0/. The Creative Commons Public Domain Dedication waiver (http://creativeco mmons.org/publicdomain/zero/1.0/) applies to the data made available in this article, unless otherwise stated in a credit line to the data. 
genes, as well as, high frequency of the transfer and exchange of resistance genes between resistant strains and virulent strains, enterococci are considered as reservoirs of antibacterial resistance genes [8]. In addition, they are important indicators of antibiotic resistance and can help in tracking the evolution of antibiotic resistance in different environments $[8,9]$.

One of the factors that could limit the development and evolution of antibiotic resistance in bacteria is clustered regularly interspaced short palindromic repeat (CRISPR)-Cas systems [10-14]. CRISPR-Cas systems are widespread among archaea and bacteria, which protect these organisms against mobile genetic elements such as phages, plasmids and transposons [10, 13-15]. The mechanism of action of these systems are included in three steps of adaptation, expression and interference [16]. Genome analysis suggested that CRISPR-Cas systems interact with mobile elements. E. faecalis has a single type of CRISPR-Cas, type II. There are three loci of CRISPR in the genomes of $E$. faecalis, which are including CRISPR1-Cas, CRISPR2 and CRISPR3-Cas [12, 17, 18]. CRISPR1-Cas were first found in the E. faecalis OG1RF strain, and is identified between the V583 homologues of open reading frames (ORFs) EF0672 and EF0673. CRISPR2 is an orphan CRISPR, consisting only of palindromes and spacers without any cas genes, and is identified between the V583 homologues of ORFs EF2062 and EF2063 [17]. CRISPR3-Cas was found in the genomes of E. faecalis strains Fly1 and T11 that is identified between the homologues of the E. faecalis V583 ORFs EF1760 and EF1759 [12]. Nmeni subtype loci marker gene cas1 and cas 2 , as well as, Nmeni subtype-specific genes $\operatorname{csn} 1$ and csn 2 were found in both CRISPR1-Cas and CRISPR3Cas $[12,17]$. Several studies have demonstrated that the CRISPR-Cas system has applications for genome engineering and exerts a strong selective pressure for the acquisition of antibiotic resistance and virulence factors in bacteria $[10-12,19]$. Therefore, in this study, we aimed to assess correlation of the CRISPR-Cas system distribution on the acquisition of antibiotic resistance among $E$. faecalis isolates.

\section{Methods and materials}

\section{Bacterial strains}

This study was approved by the Regional Ethics Committee of Tabriz (Tabriz University of Medical Sciences, Tabriz, Iran, No. IR.TBZMED.REC.1397.188). A total of 144 isolates of $E$. faecalis were collected: 75 isolates were from urinary tract infections (UTIs) and 69 isolates were from dental-root canal (DRC) infections. The UTI isolates collected from the patients admitted to Imam Reza
Teaching and Treatment Hospital and pediatric hospitals of Tabriz, Iran. The DRC isolates were collected from patients referred to the clinic of the Faculty of Dentistry at Tabriz University of Medical Sciences, Tabriz, Iran, for treatment. The DRC isolates were collected using procedure as described by Gomes et al. [20]. The paper points were transferred to a tube containing Enterococcal broth (Becton Dickenson microbiology systems, Cockeysville, $\mathrm{MD}$ ) and cultured on a bile esculin azide agar (Himedia, India) and incubated at $37^{\circ} \mathrm{C}$ for $24-48 \mathrm{~h}$ [20]. Suspected colonies were identified by the standard procedures of microbiology [21,22] and genotype detection was performed by $d d l E$ primer [23, 24], as shown in Additional file 1: Table S1. Both clinical and DRC isolates were stored in a trypticase soy broth containing $10 \%$ glycerol at $-70{ }^{\circ} \mathrm{C}$ for further studies.

\section{Phenotypic antibiotic susceptibility assay}

Disk diffusion procedure on Muller-Hinton agar medium (Merck, Germany) was performed for all E. faecalis isolates according to the clinical and laboratory standard institute (CLSI) guidelines [25]. Eleven antibiotics tested were included penicillin (10U), ampicillin $(10 \mu \mathrm{g})$, gentamicin $(120 \mu \mathrm{g})$, vancomycin $(30 \mu \mathrm{g})$, teicoplanin $(30 \mu \mathrm{g})$, erythromycin $(15 \mu \mathrm{g})$, tetracycline $(30 \mu \mathrm{g})$, ciprofloxacin $(5 \mu \mathrm{g})$, rifampin $(5 \mu \mathrm{g})$, fosfomycin $(200 \mu \mathrm{g})$ and linezolid (30 $\mu \mathrm{g})$ (Mast, UK).

In addition, minimum inhibitory concentration (MIC) of vancomycin (CAS: 1404-93-9, Sigma-Aldrich, USA) and gentamicin (CAS: 1405-41-0, Sigma-Aldrich, USA) were determined using the agar dilution procedure as recommended by CLSI [25]. Following disk diffusion and agar dilution procedures, plates were incubated at $35^{\circ} \mathrm{C}$ for 18-24 h. The MIC50 value was defined as the concentration that inhibited at least $50 \%$ of the isolates and MIC90 was defined as the concentration that inhibited at least $90 \%$ of the isolates.

\section{Genotypic detection of antibiotic resistance genes}

Total DNA of all E. faecalis isolates were extracted using tissue buffer procedure $(0.25 \%$ sodium dodecyl sulfate (SDS) and $0.05 \mathrm{M} \mathrm{NaOH}$ ). Genotypic analysis for isolates that displayed resistance to antibiotics phenotypically was accomplished for the presence of antibacterial resistance genes using polymerase chain reaction (PCR). Genes for resistance to penicillin (blaZ), macrolide (erm $A$ and $\operatorname{erm} B$ ), tetracycline (tet $M$ and tet $O$ ), vancomycin (vanA and $v a n B)$, and aminoglycoside (aac6'-aph(2"), $\operatorname{aad} E$ and $a n t(6))$ were tested among the isolates. Primers used for detection of the antibiotic resistance genes are shown in Additional file 1: Table S1. PCR amplification 
were performed in a $25 \mu \mathrm{l}$ reaction mixture using $2 \mu \mathrm{l}$ of template DNA, $2 \mathrm{mM} \mathrm{MgCl} 2,1 \mu \mathrm{M}$ of each primer and $1 \mathrm{U}$ of Taq DNA polymerase (Yekta Tajhiz Azma, Iran). The PCR products were analyzed by electrophoresis using a $1 \%$ agarose gel in $1 \mathrm{X}$ TBE buffer and the stained gels were viewed using a standard UV transilluminator. E. faecalis $\mathrm{ATCC}^{\circledR} 29,212^{\mathrm{TM}}$ and E. faecalis MMH594, E. faecium 15555EK (positive for tetM, ermB), E. faecalis 16680EK (positive for aac(6')-aph(2"); ant(6)), E. faecalis E206 (positive for vanA), E. faecalis E2781 (positive for $v a n B$ ) were used as control strains.

\section{Detection of CRISPR-Cas loci}

The presence of CRISPR loci were identified by five primer sets including three CRISPR loci and cas genes of CRISPR1 and CRISPR3 (see Additional file 1: Table S1). The mix for each loci contained $25 \mu \mathrm{l}$ of the PCR master mix (Yekta Tajhiz Azma, Iran), $2 \mu$ l of template DNA and $1 \mu \mathrm{M}$ of each primer. The amplification condition was carried out with the following thermal cycling conditions: an initial denaturation at $94{ }^{\circ} \mathrm{C}$ for $5 \mathrm{~min}, 30$ cycles of denaturation $\left(94^{\circ} \mathrm{C}\right.$ for $\left.30 \mathrm{~s}\right)$, annealing $\left(60{ }^{\circ} \mathrm{C}\right.$ for $30 \mathrm{~s}$ ), and elongation $\left(72{ }^{\circ} \mathrm{C}\right.$ for $\left.45 \mathrm{~s}\right)$, followed by final elongation at $72{ }^{\circ} \mathrm{C}$ for $5 \mathrm{~min}$. The PCR products were analyzed by electrophoresis using a $1 \%$ agarose gel in $1 \mathrm{X}$ TBE buffer and the stained gels were viewed using a standard UV transilluminator.

\section{Analysis of genotype by RAPD-PCR}

All $E$. faecalis isolates were genotyped by the single primer M13 (5'-GAGGGTGGCGGTTCT-3') [26]. Reactions were carried out in a total volume of $25 \mu \mathrm{l}$ containing $2 \mu \mathrm{l}$ of template DNA, $3 \mathrm{mM}$ of $\mathrm{MgCl} 2,1 \mu \mathrm{M}$ of M13 primer and $1 \mathrm{U}$ of Taq DNA polymerase. The PCR cycling program consisted of an initial denaturation at $94{ }^{\circ} \mathrm{C}$ for $5 \mathrm{~min}, 30$ cycles of $95^{\circ} \mathrm{C}$ for $60 \mathrm{~s}, 42^{\circ} \mathrm{C}$ for $30 \mathrm{~s}$ (with $0.6^{\circ} \mathrm{C} / \mathrm{s} \mathrm{ramp}$ ), and $72{ }^{\circ} \mathrm{C}$ for $60 \mathrm{~s}$ and a final elongation at $72{ }^{\circ} \mathrm{C}$ for $5 \mathrm{~min}$. All PCR products were separated by electrophoresis on $1.5 \%$ agarose gel in $1 \mathrm{X}$ TBE buffer and stained by ethidium bromide. All generated RAPD-PCR fingerprints were analyzed by GelJ v.2 software. The similarity matrix of the generated fingerprints was based on the Pearson product-moment correlation coefficient. A cluster analysis was deduced using the unweighted-pairgroup method with arithmetic averages (UPGMA).

\section{Statistical analysis}

SPSS software, version 20.0, (Chicago, IL, USA) was used for statistical analysis. One-tailed Fisher's exact test was used to compare the occurrence of different antibiotic resistance, genes and CRISPR-cas loci among UTIs and DRC isolates. In addition, Spearman's rank correlation coefficient was calculated between the presence of different antibiotic resistance, genes and CRISPR-cas loci among isolates. Mann-Whitney U test was used for comparison of the numbers of antibiotic resistance and related genes between isolates with and without CRISPR loci. Significance was set at $\mathrm{p}$-value $<0.05$.

\section{Results}

A total of 144 isolates of E. faecalis were included in the study, 75 isolates were from urinary tract infections (UTIs) and 69 isolates were from dental-root canal (DRC) infections. The UTI specimens were obtained from different wards including outpatients (32, 42.67\%), internal medicine ward $(18,24 \%)$, intensive-care units (ICU) (12, 16\%), infectious ward $(8,10.67 \%)$, emergency ward (3, 4\%), urology and nephrology (1, 1.33\%) and ear-nose-throat (ENT) $(1,1.33 \%)$. The age range of the patients with UTIs was from 5 months to 86 years, with a mean of $37.5( \pm 31.69)$ years. In the UTI isolates, $37(49.33 \%)$ isolates were obtained from female and 38 (50.67\%) isolates were from male patients. 45 (65.22\%) of the DRC isolates were obtained from the males and 24 $(34.78 \%)$ from the females. The age range of the endodontic treatment patients was 12-66 years, with a mean of $32.53( \pm 10.84)$ years. All isolates were investigated for the antibiotic susceptibility assay and phenotypic characteristics of antibiotic resistance among UTI and DRC isolates are shown in Table 1. Overall, the occurrence of penicillin, erythromycin, tetracycline, ciprofloxacin, teicoplanin and gentamicin resistance were present in proportionally higher numbers of UTI isolates than DRC isolates $(p<0.05)$. The results of MIC demonstrated that nine $(5.96 \%)$ isolates were resistant to vancomycin of

Table. 1 Phenotypic characteristics of UTIs and DRC isolates of E. faecalis

\begin{tabular}{llclr}
\hline Antibiotics & $\begin{array}{l}\text { Total } \\
\text { resistant } \\
\text { isolates (\%) }\end{array}$ & $\begin{array}{l}\text { UTI resistant } \\
\text { isolates (\%) }\end{array}$ & $\begin{array}{l}\text { DRC } \\
\text { resistant } \\
\text { isolates (\%) }\end{array}$ & p-value \\
\hline Ampicillin & $10(6.94 \%)$ & $7(9.33 \%)$ & $3(4.34 \%)$ & 0.199 \\
Penicillin & $33(22.92 \%)$ & $30(40.00 \%)$ & $3(4.35 \%)$ & $<0.001$ \\
Vancomycin & $10(6.94 \%)$ & $8(10.67 \%)$ & $2(2.90 \%)$ & 0.064 \\
Teicoplanin & $11(7.64 \%)$ & $9(12.00 \%)$ & $2(2.90 \%)$ & 0.038 \\
Fosfomycin & $28(19.44 \%)$ & $17(22.67 \%)$ & $11(15.94 \%)$ & 0.210 \\
Erythromycin & $70(48.61 \%)$ & $62(82.67 \%)$ & $8(11.60 \%)$ & $<0.001$ \\
Linezolid & $2(1.38 \%)$ & $2(2.67 \%)$ & 0 & 0.270 \\
Tetracycline & $87(60.42 \%)$ & $68(90.67 \%)$ & $19(27.54 \%)$ & $<0.001$ \\
Ciprofloxacin & $65(45.14 \%)$ & $49(65.33 \%)$ & $16(23.20 \%)$ & $<0.001$ \\
Gentamicin & $49(34.03 \%)$ & $41(54.67 \%)$ & $8(11.60 \%)$ & $<0.001$ \\
$\quad(128 \mu$ m) & & & & \\
Rifampin & $99(68.75 \%)$ & $49(65.33 \%)$ & $50(72.47 \%)$ & 0.229 \\
\hline
\end{tabular}

$\mathrm{p}$-value was calculated by one-tailed Fisher's exact test and $\mathrm{p}$-value $<0.05$ was significant 
which MIC50 and MIC90 were $2 \mu \mathrm{g} / \mathrm{mL}$ and $4 \mu \mathrm{g} / \mathrm{mL}$, respectively. As well as, $49(34.03 \%)$ isolates showed MIC values greater than $128 \mu \mathrm{g} / \mathrm{mL}$ against gentamicin $(\mathrm{MIC} 50<16 \mu \mathrm{g} / \mathrm{mL}$ and MIC90 $>512 \mu \mathrm{g} / \mathrm{mL})$. The MIC values of vancomycin and gentamicin of UTI and DRC isolates are shown in Table 2. In addition, the isolates resistant to more than two antibiotics were considered as multidrug resistance (MDR). Antibiotic patterns of MDR UTI and DRC isolates of E. faecalis are shown in Table 3. Overall, 59 types of antibiotic resistance patterns existed in this study, of which 44 types were MDR and there was four $(2.78 \%)$ isolates resistant to nine antibiotics, this was the highest antibiotic resistance observed. 80 out of 151 (55.56\%) isolates were considered as MDR, among which $63(78.75 \%)$ were UTI isolates and 17 (21.25\%) were DRC isolates. The antibiotic resistance counts in UTI isolates were significantly higher in comparison to DRC isolates $(\mathrm{p}<0.001)$. Antibiotic patterns of MDR UTIs and DRC isolates of E. faecalis are shown in Table 3.

The banding patterns, analyzed by GelJ software, showed ten major groups of all UTI and DRC isolates at a cut off level of $85 \%$ (Fig. 1). Overall, 14 clusters were obtained (cluster I-XIV), which each cluster contained 1-19 isolates. The UTI isolates were distributed in clusters II, III, VII, VIII, IX, X, and XIV while DRC isolates were distributed in clusters I, III, IV, V, VI, XI, XII, XIII and XIV. Therefore, clusters II, VII, VIII, IX and X contained only UTI isolates and clusters I, IV, V, VI, XI, XII and XIII contained only DRC isolates. Distribution of CRISPR loci among RAPD clusters of the isolates are shown in Table 4. There were six clusters with isolates containing CRISPR1 and eight clusters without it, which the most frequent of isolates with CRISPR1 were found in clusters II (4 isolates) and III (5 isolates). The most frequent of isolates with CRISPR2 were found in clusters III (15 isolates) and IX (13 isolates), while it was not found in cluster I. As well as, there were 7 clusters with isolates that without CRISPR3 and the most frequent clusters were III ( 8 isolates) and XII (5 isolates).

The occurrence of antibacterial resistance genes in E. faecalis isolates of UTI and DRC isolates is shown in Table 5. Overall, aadE (69.44\%) and tetM (63.89\%) genes were present in most samples, while ermA $(3.47 \%)$ and tetO $(4.17 \%)$ genes were present in least of them; none of the samples were found to possess $v a n B$. The occurrence of tet $M, \operatorname{erm} A, \operatorname{erm} B, v a n A$, aac6'-aph(2"), aadE and ant(6) in UTI isolates were significantly predominant in comparison to DRC isolates $(\mathrm{p}<0.05)$. In addition, the resistance genes counts in UTI isolates were significantly predominant in comparison to DRC isolates $(\mathrm{p}<0.001)$. As well as, the results demonstrated that the resistance genes counts were directly associated with antibiotic resistance counts $(\mathrm{p}<0.001)$. The antibiotic resistance gene patterns among UTIs and DRC isolates of E. faecalis are shown in Table 6.

The occurrence of CRISPR-cas in E. faecalis isolates of UTI and DRC isolates is shown in Table 7. Overall, CRISPR2 was identified in 77 (53.47\%) of the isolates, followed by CRISPR3 and CRISPR1 (17.75 and 10.42\%, respectively). The correlation between antibiotic resistance and antibiotic resistance genes counts and the occurrence of CRISPR loci are shown in Fig. 2. The presence of CRISPR 2 and CRISPR3 were indirectly associated to the counts of resistant antibiotics and related genes among the isolates $(\mathrm{p}<0.05)$. The correlation between the presence of CRISPR-Cas and phenotypic antibiotic resistance were shown in Fig. 3. Overall, CRISPR2 was predominant in gentamicin and rifampin susceptible isolates $(\mathrm{p}=0.009$ and $\mathrm{p}=0.054$, respectively). In addition, CRISPR3 was predominant in erythromycin, tetracycline, ciprofloxacin and gentamicin susceptible isolates $(\mathrm{p}<0.001, \mathrm{p}=0.002, \mathrm{p}=0.002$ and $\mathrm{p}<0.001$, respectively). No correlation was found between CRISPR1 and antibiotic resistance. The absence of CRISPR3 was significantly associated with the increased values of vancomycin MIC ( $<<0.001)$. As well as, the absence of CRISPR2 and CRISPR3 were significantly associated to the increased values of gentamicin MIC $(p=0.038$ and $p<0.001$, respectively). In UTI isolates, CRISPR2 was predominant in fosfomycin, ampicillin, and teicoplanin susceptible

Table. 2 MIC values of vancomycin and gentamicin among UTIs and DRC isolates of E. faecalis

\begin{tabular}{llllllll}
\hline $\begin{array}{l}\text { MIC of } \\
\text { vancomycin }\end{array}$ & Total isolates (\%) & UTI isolates (\%) & DRC isolates (\%) & $\begin{array}{l}\text { MIC of } \\
\text { gentamicin }\end{array}$ & Total isolates (\%) & UTI isolates (\%) & DRC isolates (\%) \\
\hline $1 \geq$ & $70(48.61 \%)$ & $35(46.67 \%)$ & $35(50.72 \%)$ & $16>$ & $91(63.19 \%)$ & $33(44.00 \%)$ & $58(84.06 \%)$ \\
2 & $55(38.19 \%)$ & $24(32.00 \%)$ & $31(44.93 \%)$ & 64 & $4(2.78 \%)$ & $1(1.33 \%)$ & $3(4.35 \%)$ \\
4 & $9(6.25 \%)$ & $9(10.67 \%)$ & $1(1.45 \%)$ & 256 & 0 & 0 & 0 \\
8 & $1(0.69 \%)$ & 0 & $1(1.45 \%)$ & 512 & $6(4.17 \%)$ & $6(8.00 \%)$ & 0 \\
256 & $2(1.39 \%)$ & $1(1.33 \%)$ & $1(1.45 \%)$ & $512<$ & $43(29.86 \%)$ & $35(46.67 \%)$ & $8(11.59 \%)$ \\
$512<$ & $7(4.86 \%)$ & $7(9.33 \%)$ & 0 & - & - & - & - \\
\hline
\end{tabular}


Table. 3 Antibiotic patterns of MDR UTIs and DRC isolates of E. faecalis

\begin{tabular}{|c|c|c|c|c|}
\hline $\begin{array}{l}\text { Antibiotics to which isolates } \\
\text { showed resistance }\end{array}$ & No. of antibiotic & Total isolates (\%) & UTI isolates (\%) & DRC isolates (\%) \\
\hline $\mathrm{F}, \mathrm{Tt}, \mathrm{R}$ & 3 & $2(1.39 \%)$ & $1(1.33 \%)$ & $1(1.45 \%)$ \\
\hline$E, T t, R$ & 3 & $4(2.78 \%)$ & $4(5.33 \%)$ & 0 \\
\hline$E, T, G$ & 3 & $1(0.69 \%)$ & $1(1.33 \%)$ & 0 \\
\hline$T t, C, R$ & 3 & $4(2.78 \%)$ & $3(4.00 \%)$ & $1(1.45 \%)$ \\
\hline$E, C, R$ & 3 & $1(0.69 \%)$ & $1(1.33 \%)$ & 0 \\
\hline $\mathrm{E}, \mathrm{Tt}, \mathrm{G}$ & 3 & $1(0.69 \%)$ & $1(1.33 \%)$ & 0 \\
\hline $\mathrm{E}, \mathrm{Tt}, \mathrm{C}$ & 3 & $1(0.69 \%)$ & $1(1.33 \%)$ & 0 \\
\hline $\mathrm{E}, \mathrm{P}, \mathrm{Tt}$ & 3 & $1(0.69 \%)$ & $1(1.33 \%)$ & 0 \\
\hline $\mathrm{Tt}, \mathrm{G}, \mathrm{R}$ & 3 & $1(0.69 \%)$ & 0 & $1(1.45 \%)$ \\
\hline$E, G, R$ & 3 & $5(3.47 \%)$ & 0 & $5(7.25 \%)$ \\
\hline $\mathrm{A}, \mathrm{P}, \mathrm{Tt}$ & 3 & $1(0.69 \%)$ & 0 & $1(1.45 \%)$ \\
\hline$A, P, C$ & 3 & $1(0.69 \%)$ & 0 & $1(1.45 \%)$ \\
\hline $\mathrm{F}, \mathrm{Tt}, \mathrm{C}$ & 3 & $1(0.69 \%)$ & 0 & $1(1.45 \%)$ \\
\hline$F, P, T t, R$ & 4 & $1(0.69 \%)$ & $1(1.33 \%)$ & 0 \\
\hline $\mathrm{E}, \mathrm{Tt}, \mathrm{C}, \mathrm{R}$ & 4 & $1(0.69 \%)$ & $1(1.33 \%)$ & 0 \\
\hline$E, T t, C, G$ & 4 & $4(2.78 \%)$ & $4(5.33 \%)$ & 0 \\
\hline $\mathrm{E}, \mathrm{P}, \mathrm{Tt}, \mathrm{R}$ & 4 & $2(1.39 \%)$ & $2(2.67 \%)$ & 0 \\
\hline $\mathrm{E}, \mathrm{Tt}, \mathrm{G}, \mathrm{R}$ & 4 & $2(1.39 \%)$ & $2(2.67 \%)$ & 0 \\
\hline$E, L, T t, R$ & 4 & $1(0.69 \%)$ & $1(1.33 \%)$ & 0 \\
\hline $\mathrm{P}, \mathrm{Tt}, \mathrm{C}, \mathrm{G}$ & 4 & $1(0.69 \%)$ & $1(1.33 \%)$ & 0 \\
\hline $\mathrm{F}, \mathrm{Tt}, \mathrm{T}, \mathrm{R}$ & 4 & $2(1.39 \%)$ & 0 & $2(2.90 \%)$ \\
\hline$E, C, G, R$ & 4 & $1(0.69 \%)$ & 0 & $1(1.45 \%)$ \\
\hline $\mathrm{F}, \mathrm{Tt}, \mathrm{C}, \mathrm{R}$ & 4 & $1(0.69 \%)$ & 0 & $1(1.45 \%)$ \\
\hline $\mathrm{E}, \mathrm{Tt}, \mathrm{C}, \mathrm{G}, \mathrm{R}$ & 5 & 7 (4.86\%) & 7 (9.33\%) & 0 \\
\hline$E, A, P, T t, C$ & 5 & $1(0.69 \%)$ & $1(1.33 \%)$ & 0 \\
\hline$E, P, T t, C, R$ & 5 & $1(0.69 \%)$ & $1(1.33 \%)$ & 0 \\
\hline $\mathrm{E}, \mathrm{P}, \mathrm{Tt}, \mathrm{G}, \mathrm{R}$ & 5 & $1(0.69 \%)$ & $1(1.33 \%)$ & 0 \\
\hline $\mathrm{E}, \mathrm{P}, \mathrm{Tt}, \mathrm{C}, \mathrm{G}$ & 5 & $3(2.08 \%)$ & $3(4.00 \%)$ & 0 \\
\hline$F, E, A, P, T t$ & 5 & 1 (0.69\%) & 0 & $1(1.45 \%)$ \\
\hline $\mathrm{F}, \mathrm{E}, \mathrm{Tt}, \mathrm{C}, \mathrm{R}$ & 5 & $1(0.69 \%)$ & 0 & $1(1.45 \%)$ \\
\hline $\mathrm{E}, \mathrm{L}, \mathrm{Tt}, \mathrm{C}, \mathrm{G}, \mathrm{R}$ & 6 & $1(0.69 \%)$ & $1(1.33 \%)$ & 0 \\
\hline$F, E, T t, C, G, R$ & 6 & $4(2.78 \%)$ & $4(5.33 \%)$ & 0 \\
\hline $\mathrm{E}, \mathrm{P}, \mathrm{Tt}, \mathrm{C}, \mathrm{G}, \mathrm{R}$ & 6 & 7 (4.86\%) & 7 (9.33\%) & 0 \\
\hline $\mathrm{V}, \mathrm{E}, \mathrm{Tt}, \mathrm{C}, \mathrm{G}, \mathrm{T}$ & 6 & $1(0.69 \%)$ & $1(1.33 \%)$ & 0 \\
\hline$F, E, P, T t, C, G, R$ & 7 & $1(0.69 \%)$ & $1(1.33 \%)$ & 0 \\
\hline$F, E, A, P, T t, C, G$ & 7 & $1(0.69 \%)$ & $1(1.33 \%)$ & 0 \\
\hline$V, F, E, P, T t, C, T$ & 7 & $1(0.69 \%)$ & $1(1.33 \%)$ & 0 \\
\hline $\mathrm{E}, \mathrm{A}, \mathrm{P}, \mathrm{Tt}, \mathrm{C}, \mathrm{G}, \mathrm{R}$ & 7 & $1(0.69 \%)$ & $1(1.33 \%)$ & 0 \\
\hline$F, E, P, T t, C, G, T, R$ & 8 & $1(0.69 \%)$ & $1(1.33 \%)$ & 0 \\
\hline$V, F, E, A, P, C, G, T$ & 8 & $1(0.69 \%)$ & $1(1.33 \%)$ & 0 \\
\hline$F, E, A, P, T t, C, G, R$ & 8 & $1(0.69 \%)$ & $1(1.33 \%)$ & 0 \\
\hline $\mathrm{V}, \mathrm{F}, \mathrm{E}, \mathrm{P}, \mathrm{Tt}, \mathrm{C}, \mathrm{G}, \mathrm{T}$ & 8 & $1(0.69 \%)$ & $1(1.33 \%)$ & 0 \\
\hline$V, F, E, P, T t, C, G, T, R$ & 9 & $2(1.39 \%)$ & $2(2.67 \%)$ & 0 \\
\hline$V, F, E, A, P, T, C, T, R$ & 9 & $1(0.69 \%)$ & $1(1.33 \%)$ & 0 \\
\hline$V, F, E, A, P, C, G, T, R$ & 9 & $1(0.69 \%)$ & $1(1.33 \%)$ & 0 \\
\hline Total & - & $80(55.55 \%)$ & $63(78.75 \%)$ & $17(21.25 \%)$ \\
\hline
\end{tabular}

$V$ Vancomycin, $F$ Fosfomycin, E Erythromycin, A Ampicillin, L Linezolid, $P$ Penicillin, $T$ t Tetracycline, C Ciprofloxacin, G Gentamicin, $T$ Teicoplanin, $R$ Rifampin 
Fig. 1 Cluster analysis of genetic fingerprints of UTIs and DRC isolates of $E$. faecalis by the use of RAPD-PCR. The similarity matrix of the generated fingerprints was based on the Pearson product-moment correlation coefficient. A cluster analysis was deduced using the unweighted-pair-group method with arithmetic averages (UPGMA). The isolates differentiation was achieved at a cut off level of $85 \%$. Overall, fourteen clusters were included I-XIV, which each cluster contained 4-19 isolates exception of cluster VIII and XIII that cluster XIII had 1 isolate of the DRC and cluster VIII had 2 isolates of the UTIs isolates $(\mathrm{p}=0.032, \mathrm{p}=0.042$, and $\mathrm{p}=0.059$, respectively). In addition, CRISPR2 was predominant in tetracycline resistance isolates $(\mathrm{p}=0.004)$. In DRC isolates, CRISPR2 was predominant in rifampin and gentamicin susceptible isolates ( $\mathrm{p}=0.049$ and $\mathrm{p}=0.001$, respectively).

Overall, the presence of CRISPR1 was found to have direct association with the absence of tet $M$ and $\operatorname{erm} B$ ( $\mathrm{p}=0.043$ and $\mathrm{p}=0.032$, respectively). The presence of CRISPR2 was directly associated to the absence of $v a n A$, $\operatorname{aac6}-\operatorname{aph}\left(2^{\prime \prime}\right)$ and aadE genes $(\mathrm{p}=0.0054, \mathrm{p}=0.049$, and $\mathrm{p}=0.015$, respectively). As well as, the presence of CRISPR3 was directly associated to the absence of tet $M$, $\operatorname{ermB}, \operatorname{aac6}-\operatorname{aph}(2))$, aadE, and $\operatorname{ant}(6)$ genes $(\mathrm{p}<0.001$ for all genes). In UTI isolates, relative association was found between the presence of CRISPR2 and the absence of tet $O$ genes ( $\mathrm{p}=0.067$, respectively). In DRC isolates, indirect association was found between the presence of CRISPR2 and the absence of ermB, aac6'-aph(2"), aadE and ant(6) genes $(\mathrm{p}=0.028, \mathrm{p}=0.006, \mathrm{p}=0.053$, and $\mathrm{p}=0.086$, respectively), as well as, between presence of CRISPR3 and the absence of $a a d E$ gene $(\mathrm{p}=0.021)$.

\section{Discussion}

In this study, we examined $75 \mathrm{E}$. faecalis isolates from patients with UTIs and $69 \mathrm{E}$. faecalis isolates from patients with DRC infection to determine the relationship between CRISPR loci and antibiotic resistance among $E$. faecalis isolates. The occurrence of antibiotic resistance genes, the cas genes or resistance to antibiotics showed no distinct distribution within the groups of RAPD-PCR clustering, which are consistent with Linderstrauss et al. [27], who that found similar results for the occurrence of virulence genes and the cas genes. The current study demonstrated that the presence of CRISPR loci was variable among $E$. faecalis isolates, which the presence of CRISPR1 was in the lowest frequency among the isolates and CRISPR2 was the highest locus (53.47\%). In contrast our study, Palmer and Gilmore [12] found that CRISPR2 were present in all E. faecalis isolates. In addition, similar to our study, Palmer and Gilmore [12] found that one-third of isolates possess one of the CRISPR1 or CRISPR3. Our results demonstrated that

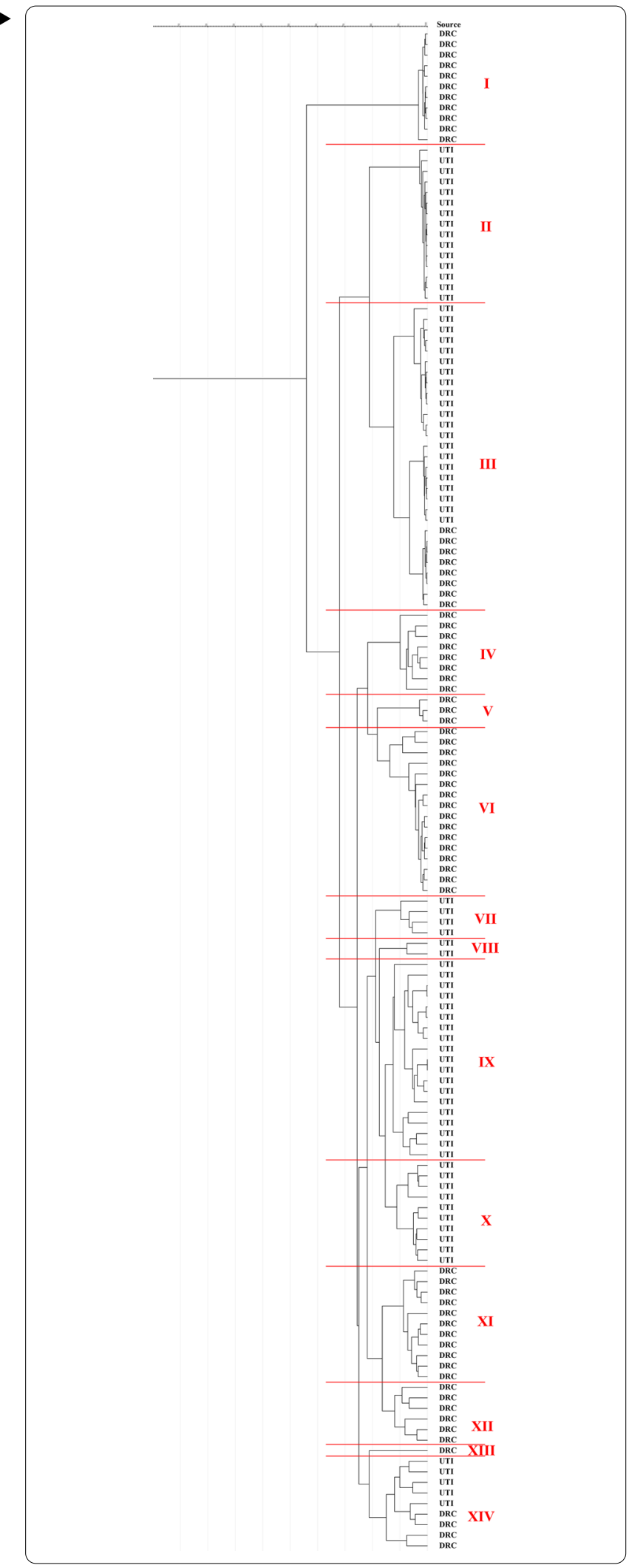


Table. 4 Distribution of CRISPR loci among RAPD clusters of E. faecalis isolates

\begin{tabular}{|c|c|c|c|c|c|c|}
\hline RAPD types & CRISPR1-Present & CRISPR1-Absent & CRISPR2-Present & CRISPR2-Absent & CRISPR3-Present & $\begin{array}{l}\text { CRISPR3- } \\
\text { Absent }\end{array}$ \\
\hline | & 0 & 11 & 0 & 11 & 3 & 8 \\
\hline$\|$ & 4 & 11 & 4 & 11 & 0 & 15 \\
\hline III & 5 & 24 & 15 & 14 & 8 & 21 \\
\hline IV & 0 & 8 & 5 & 3 & 2 & 6 \\
\hline V & 1 & 7 & 7 & 1 & 0 & 8 \\
\hline VI & 2 & 9 & 3 & 8 & 1 & 10 \\
\hline VII & 0 & 4 & 1 & 3 & 0 & 4 \\
\hline VIII & 1 & 1 & 2 & 0 & 0 & 2 \\
\hline IX & 2 & 17 & 13 & 6 & 0 & 19 \\
\hline$x$ & 0 & 10 & 5 & 5 & 0 & 10 \\
\hline$X I$ & 0 & 11 & 11 & 0 & 4 & 7 \\
\hline XII & 0 & 6 & 4 & 2 & 5 & 1 \\
\hline XIII & 0 & 1 & 1 & 0 & 0 & 1 \\
\hline XIV & 0 & 9 & 6 & 3 & 4 & 5 \\
\hline
\end{tabular}

Table. 5 Occurrence of antibiotic resistance-related genes among UTIs and DRC isolates of E. faecalis

\begin{tabular}{lllll}
\hline Gene & Total isolates (\%) & UTI isolates (\%) & DRC isolates (\%) & p-value \\
\hline blaZ & $8(5.56 \%)$ & $2(2.67 \%)$ & $6(8.70 \%)$ & 0.112 \\
tetM & $92(63.89 \%)$ & $71(94.67 \%)$ & $21(30.43 \%)$ & $1(1.45 \%)$ \\
tetO & $6(4.17 \%)$ & $5(6.67 \%)$ & 0 & 0.125 \\
ermA & $5(3.47 \%)$ & $5(6.67 \%)$ & $7(10.14 \%)$ & 0.036 \\
ermB & $59(40.97 \%)$ & $52(69.33 \%)$ & $1(1.45 \%)$ & $<01$ \\
vanA & $9(6.25 \%)$ & $8(10.67 \%)$ & 0 & 0.023 \\
vanB & 0 & 0 & $6(8.70 \%)$ & $<$ \\
aac6'-aph(2") & $49(34.03 \%)$ & $43(57.33 \%)$ & $36(52.17 \%)$ & $<0.001$ \\
aadE & $100(69.44 \%)$ & $64(85.33 \%)$ & $3(4.35 \%)$ & $<0.001$ \\
ant(6) & $50(34.72 \%)$ & $47(62.67 \%)$ & & $<0.001$ \\
\hline
\end{tabular}

p-value was calculated by one-tailed Fisher's exact test and $p$-value $<0.05$ was significant

co-occurrence of CRISPR1 and CRISPR3 was not found in the same isolates, which is similar to Palmer and Gilmore [12] and Linderstrauss et al. [27], while Burley and Sedgley [28] found the co-occurrence of these two loci in three endodontic isolates $(0.03 \%)$ out of a total of 88 endodontic, oral and hospital acquired isolates. Similarly to our study, Burley and Sedgley [28] demonstrated that the presence of CRISPR3 in endodontic isolates was more than CRISPR1 in comparison to UTI isolates. In addition, the presence of CRISPR loci among the DRC E. faecalis isolates was significantly higher than for UTIs isolates which were multi-drug resistant isolates, which as similar to Burley and Sedgley study [28]. The reason of higher presence of CRISPR loci among the DRC isolates is not clear but could confer low antibiotic resistance to them. In addition, Lyons et al. [29] suggested that the differences between incidences of CRISPR1 among the different species of enterococci may be associated with a tradeoff protection and adaptability, as well as, the differences in the habitats of different species of enterococci may be related to varying selective pressure exerted on them, which may results in a species-dependent distribution of CRISPR-cas systems. The possible mechanisms for these results are differential activity or expression of anti-CRISPR regulators or differential transcriptional regulation of cas genes in the conditions of in vivo and in vitro $[30,31]$ that may regulate CRISPR-cas systems of E. faecalis in different environments.

The lack of cas genes as functional genes among isolates with CRISPR2, as well as, the absence of some antibiotic resistance genes such as vanA, aadE and aac6'-aph(2"), indicates that CRISPR2 alone does not confer immunity in E. faecalis. Similar results were observed by Palmer and Gilmore [12]. Hullahalli et al. [32] demonstrated that CRISPR2 could be reactivated in MDR strains for genome defense. Several studies demonstrated that the 
Table. 6 Antibiotic resistance gene patterns of UTIs and DRC isolates of E. faecalis

\begin{tabular}{|c|c|c|c|c|}
\hline Resistance gene profiles & No. of genes & Total (\%) & UTI isolates (\%) & DRC isolates (\%) \\
\hline 0 & 0 & $23(15.97 \%)$ & 0 & $23(33.33 \%)$ \\
\hline tM & 1 & $10(6.94 \%)$ & $4(5.33 \%)$ & $6(8.70 \%)$ \\
\hline $\mathrm{aE}$ & 1 & $14(9.72 \%)$ & 0 & $14(20.29 \%)$ \\
\hline bZ & 1 & $1(0.69 \%)$ & 0 & $1(1.45 \%)$ \\
\hline$t M, e A$ & 2 & $1(0.69 \%)$ & $1(1.33 \%)$ & 0 \\
\hline $\mathrm{tM}, \mathrm{aE}$ & 2 & $16(11.11 \%)$ & $7(9.33 \%)$ & $9(13.04 \%)$ \\
\hline$t M, e B$ & 2 & $3(2.08 \%)$ & $2(2.67 \%)$ & $1(1.45 \%)$ \\
\hline $\mathrm{tO}, \mathrm{aE}$ & 2 & $2(1.39 \%)$ & $1(1.33 \%)$ & $1(1.45 \%)$ \\
\hline tM, at6 & 2 & $1(0.69 \%)$ & $1(1.33 \%)$ & 0 \\
\hline $\mathrm{a} 6, \mathrm{aE}$ & 2 & $1(0.69 \%)$ & 0 & $1(1.45 \%)$ \\
\hline bZ, aE & 2 & $4(2.78 \%)$ & 0 & $4(5.80 \%)$ \\
\hline $\mathrm{bZ}, \mathrm{tM}$ & 2 & $1(0.69 \%)$ & 0 & $1(1.45 \%)$ \\
\hline$t M, v A$ & 2 & $1(0.69 \%)$ & 0 & $1(1.45 \%)$ \\
\hline $\mathrm{tM}, \mathrm{eA}, \mathrm{aE}$ & 3 & $1(0.69 \%)$ & $1(1.33 \%)$ & 0 \\
\hline $\mathrm{tM}, \mathrm{a6}, \mathrm{aE}$ & 3 & $5(3.47 \%)$ & $4(5.33 \%)$ & $1(1.45 \%)$ \\
\hline $\mathrm{tM}, \mathrm{tO}, \mathrm{aE}$ & 3 & $1(0.69 \%)$ & $1(1.33 \%)$ & 0 \\
\hline $\mathrm{tM}, \mathrm{eB}, \mathrm{aE}$ & 3 & $5(3.47 \%)$ & $3(4.00 \%)$ & $2(2.90 \%)$ \\
\hline $\mathrm{tM}, \mathrm{tO}, \mathrm{eB}$ & 3 & $1(0.69 \%)$ & $1(1.33 \%)$ & 0 \\
\hline $\mathrm{eB}, \mathrm{a} 6, \mathrm{aE}$ & 3 & $1(0.69 \%)$ & 0 & $1(1.45 \%)$ \\
\hline tM, eA, a6, aE & 4 & $1(0.69 \%)$ & $1(1.33 \%)$ & 0 \\
\hline tM, eA, eB, a6 & 4 & $1(0.69 \%)$ & $1(1.33 \%)$ & 0 \\
\hline $\mathrm{tM}, \mathrm{eB}, \mathrm{aE}, \mathrm{at} 6$ & 4 & $8(5.56 \%)$ & $8(10.67 \%)$ & 0 \\
\hline tM, eB, a6, aE & 4 & $1(0.69 \%)$ & $1(1.33 \%)$ & 0 \\
\hline eB, a6, aE, at6 & 4 & $4(2.78 \%)$ & $1(1.33 \%)$ & $3(4.35 \%)$ \\
\hline tM, eB, a6, at6 & 4 & $1(0.69 \%)$ & $1(1.33 \%)$ & 0 \\
\hline tM, eB, a6, aE, at6 & 5 & $25(17.36 \%)$ & $25(33.33 \%)$ & 0 \\
\hline $\mathrm{bZ}, \mathrm{tM}, \mathrm{a} 6, \mathrm{aE}, \mathrm{at} 6$ & 5 & $1(0.69 \%)$ & $1(1.33 \%)$ & 0 \\
\hline$e B, v A, a 6, a E$, at6 & 5 & $2(1.39 \%)$ & $2(2.67 \%)$ & 0 \\
\hline $\mathrm{tM}, \mathrm{eB}, \mathrm{vA}, \mathrm{aE}$, at6 & 5 & $1(0.69 \%)$ & $1(1.33 \%)$ & 0 \\
\hline $\mathrm{bZ}, \mathrm{tM}, \mathrm{vA}, \mathrm{aE}, \mathrm{at} 6$ & 5 & $1(0.69 \%)$ & $1(1.33 \%)$ & 0 \\
\hline tM, tO, eB, a6, aE, at6 & 6 & $2(1.39 \%)$ & $2(2.67 \%)$ & 0 \\
\hline $\mathrm{tM}, \mathrm{eB}, \mathrm{vA}, \mathrm{a} 6, \mathrm{aE}, \mathrm{at} 6$ & 6 & $3(2.08 \%)$ & $3(4.00 \%)$ & 0 \\
\hline tM, eA, eB, vA, a6, aE, at6 & 7 & $1(0.69 \%)$ & $1(1.33 \%)$ & 0 \\
\hline Total & - & $144(100 \%)$ & $80(100 \%)$ & $69(100 \%)$ \\
\hline
\end{tabular}

bZ: blaZ; tM: tetM; tO: tetO; eA: ermA; eB: ermB; vA: vanA; a6: aac(6')-aph(2"); aE: aadE; at6: ant(6)

consensus repeat sequences of CRISPR1 and CRISPR2 loci are identical and they suggested that these two loci are functionally linked [17, 33-35]. Price et al. [35] demonstrated that an orphan CRISPR2 locus cannot provide defense on its own and requires CRISPR1-cas to provide genome defense against mobile genomic elements.

In our study, there was a significant association between phenotypic antibiotic resistance, the presence of antibiotic resistance-related genes and the absence of CRISPR loci. Similarly, Burley and Sedgley [28] and
Palmer and Gilmore [12] reported that multi-drug resistance was associated with a lack of CRISPR loci. Similar to our study, they [28] found that the absence of antibiotic resistance was associated with the presence of CRISPR3, not CRISPR1. Several studies were proposed that the presence of CRISPR1 among E. faecalis is associated with the low prophage content in the strains such as E. faecalis OG1RF [17, 36, 37]. However, Bourgogne et al. [17] found that $E$. faecalis V583 lacks CRISPR1 and possesses seven prophage elements, which is in contrast with its 
Table. 7 Occurrence of CRISPR-cas among UTIs and DRC isolates of E. faecalis

\begin{tabular}{|c|c|c|c|c|}
\hline CRISPR locus & Total (\%) & UTI isolates (\%) & DRC isolates (\%) & p-value \\
\hline CRISPR1 & $15(10.42 \%)$ & $12(16.00 \%)$ & $3(4.35 \%)$ & 0.020 \\
\hline CRISPR2 & $77(53.47 \%)$ & $39(52.00 \%)$ & $38(55.07 \%)$ & 0.420 \\
\hline CRISPR3 & $27(17.75 \%)$ & $1(1.33 \%)$ & $26(37.68 \%)$ & $<0.001$ \\
\hline CRISPR1 + CRISPR2 & $11(7.64 \%)$ & $8(10.67 \%)$ & $3(4.35 \%)$ & 0.133 \\
\hline CRISPR1 + CRISPR3 & 0 & 0 & 0 & - \\
\hline CRISPR2 + CRISPR3 & $16(11.11 \%)$ & $1(1.33 \%)$ & $15(21.74 \%)$ & $<0.001$ \\
\hline CRISPR1 + CRISPR2 + CRISPR3 & 0 & 0 & 0 & - \\
\hline CRISPR1 / CRISPR2 & $82(56.94 \%)$ & $43(57.33 \%)$ & $39(56.52 \%)$ & 0.528 \\
\hline CRISPR1 / CRISPR3 & $42(29.17 \%)$ & $13(17.33 \%)$ & $29(42.03 \%)$ & 0.001 \\
\hline CRISPR2 / CRISPR3 & $88(61.11 \%)$ & $39(52.00 \%)$ & 49 (71.01\%) & 0.015 \\
\hline CRISPR1 / CRISPR2 / CRISPR3 & $92(63.89 \%)$ & $43(57.33 \%)$ & 49 (71.01\%) & 0.062 \\
\hline
\end{tabular}

$p$-value was calculated by one-tailed Fisher's exact test and $p$-value $<0.05$ was significant

function. They suggested that it might be associated with CRISPR1 locus variation in the E. faecalis species. These variably distribution was indicated in our study and study [12]. Palmer and Gilmore [12] demonstrated that the presence of CRISPR1 was present in 5/16 isolates and the presence occurred in variability between homologous of EF0672 and EF0673. In addition, their results indicated that the number of spacers in the CRISPR1 locus is varied and there is an unknown function gene between the 3'-end of CRISPR1 arrays and EF0673, which may confer variability of CRISPR activity in different species against antibiotic resistance genes [12].

Due to the fact that antibiotic resistance genes are commonly disseminated by plasmids in E. faecalis [38], CRISPR-cas may acts as a barrier to the acquisition of the antibiotic resistance genes. This is demonstrated by our results that the presence of CRISPR3 is significantly associated with the absence of some antibiotic resistance genes acquired by horizontal gene transfer such as aminoglycoside, tetracycline and erythromycin resistance-related genes, which are supported by
Palmer and Gilmore [12], who found similar results in a collection of 48 E. faecalis strains. Price et al. [35] demonstrated that CRISPR3-cas is active for sequencespecific genome defense, which was observed in availability of CRISPR3-mutant of T11 that acquired cas 9 $(\Delta \operatorname{cas} 9+\mathrm{CRISPR} 3)$ to interference and impacts on pAD1 acquisition. They also observed that deletion of only two loci can lead to a significant reduction in genome defense against clinically mobile genome elements [35].

This study supported that the occurrence of CRISPR loci is associated with the reduction of acquired antibiotic resistance genes, demonstrated with a reduced level of antibiotic resistance in E. faecalis. The inverse relationships between CRISPR loci and phenotypic and genotypic antibiotic resistance may provide novel insights to combat with the infection caused by resistant pathogens. CRISPR loci and other genetic markers could be used for infections control by E. faecalis, to give insights into their phenotypic traits and genetic contents, as well as, to differentiate low-risk strains of E. faecalis from high-risk strains. 


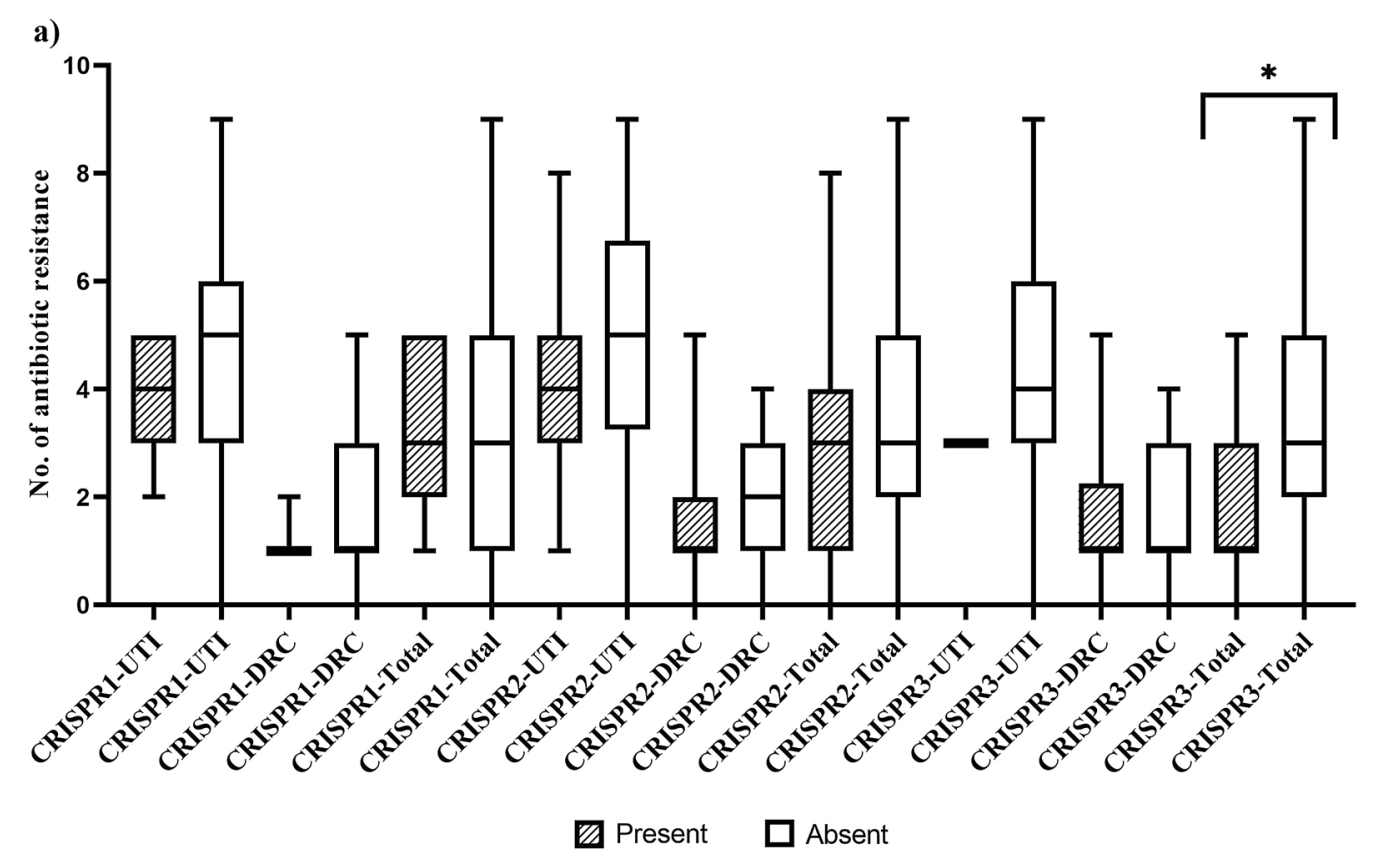

b)

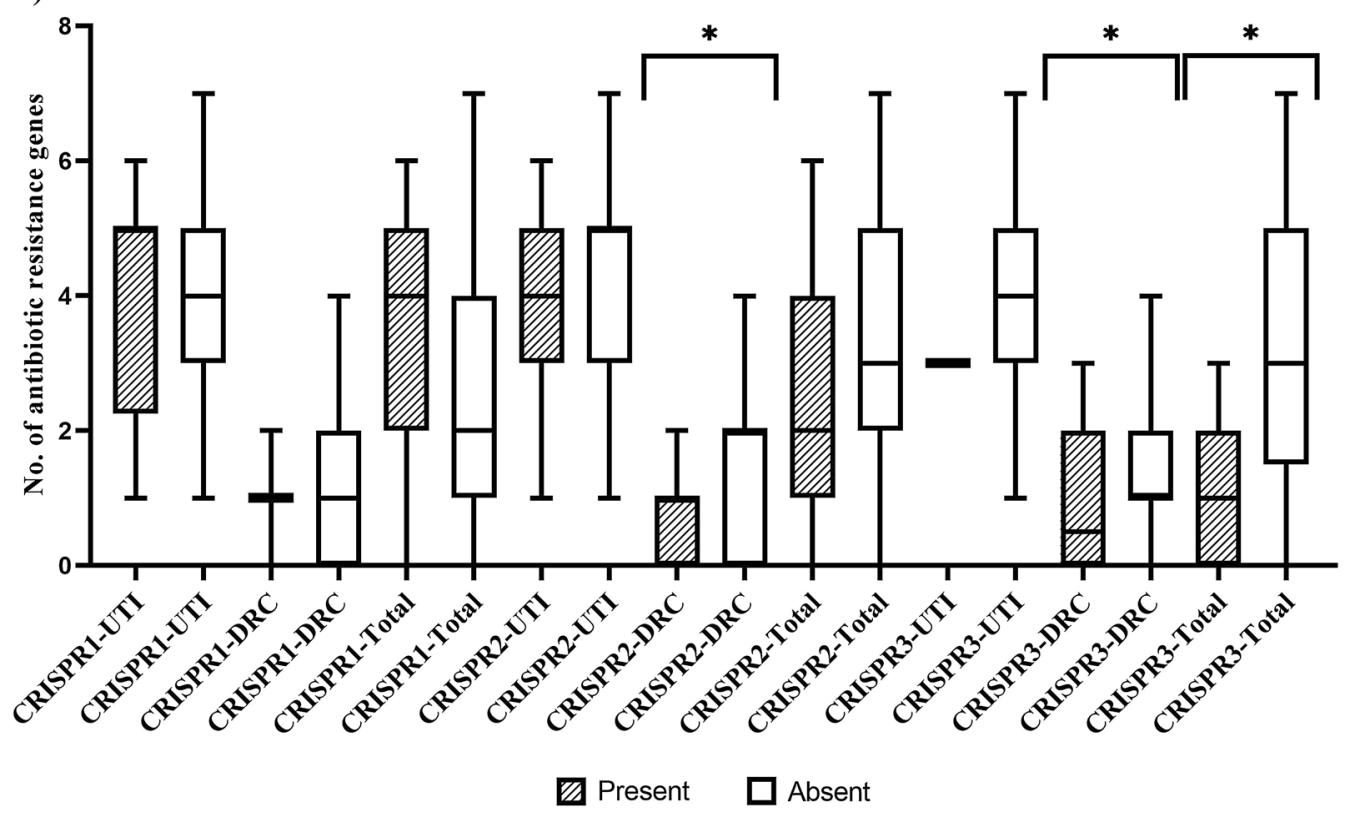

Fig. 2 Correlation between the Number of resistant antibiotics (a) and antibiotic resistance genes (b) in each E. faecalis isolate and occurrence of CRISPR loci. Note: *: p-value was significant ( $p$-value $<0.05$ ), which was calculated by U Mann-Whitney test 


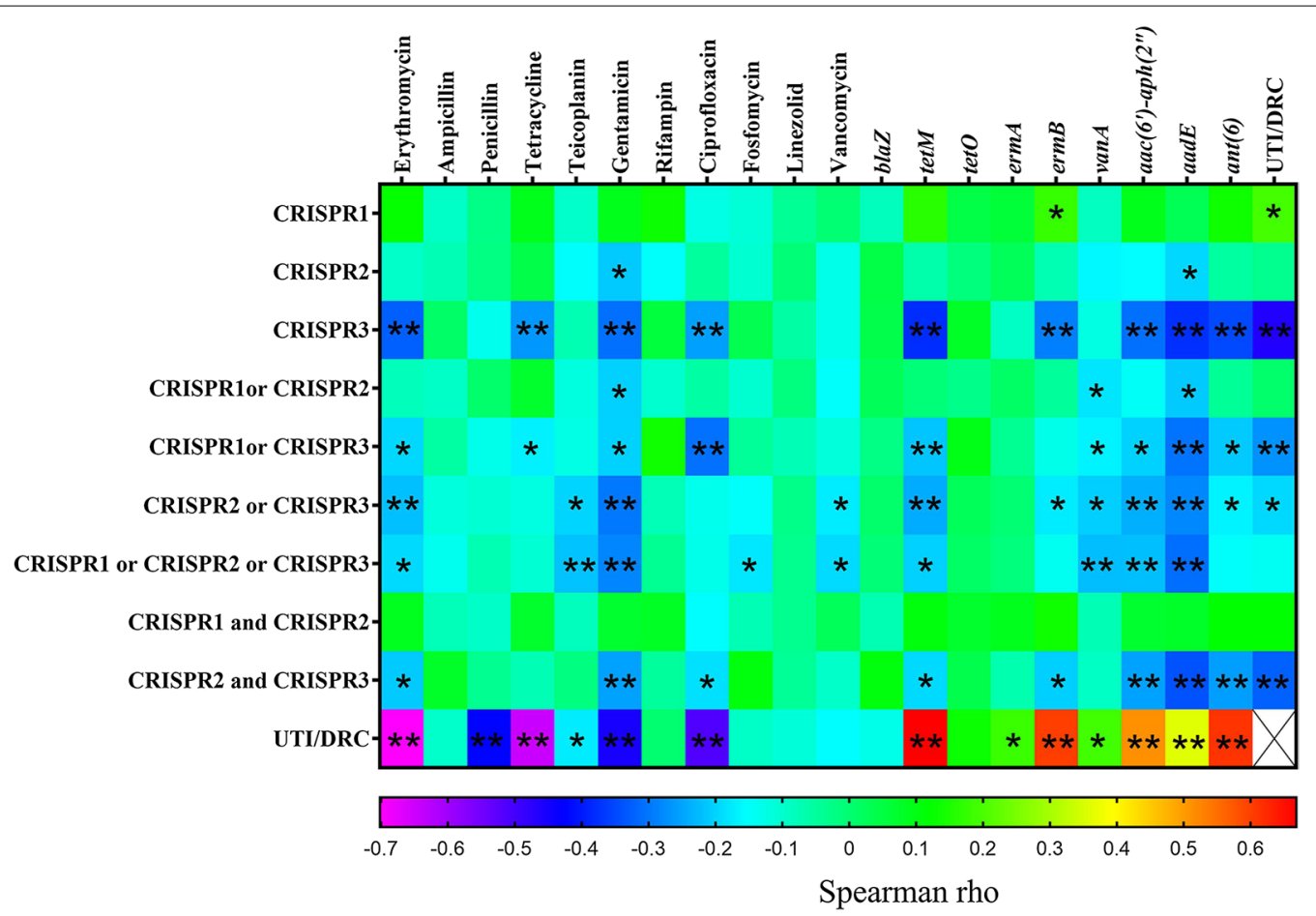

Fig. 3 Correlation between antibiotic resistance, genes and CRISPR loci among E. faecalis isolates $(-0.380<$ Spearman rho <0.178). Note: *: Correlation is significant at the 0.05 level; **: Correlation is significant at the 0.01 level. Correlations were calculated by Spearman's rank correlation coefficient

\section{Supplementary Information}

The online version contains supplementary material available at https://doi. org/10.1186/s12941-021-00455-6.

Additional file 1: Table S1. Primers used for the detection of antibiotic resistance genes and CRISPR-associated genes among E. faecalis isolates.

\section{Acknowledgements}

We thank Drug Applied Research Center, Tabriz University of Medical Sciences for all their supports.

\section{Authors' contributions}

PG: Study design, sample collection, Molecular analysis, Data analysis, Manuscript preparation, Final proof. MA: Study design, Manuscript preparation, Final proof. RG: Study design, Manuscript preparation, Final proof. MAR: Study design, Data analysis, Final proof. TP: Study design, Data analysis, Final proof. LC: Manuscript preparation, Final proof. SW: Manuscript preparation, Final proof. HF: Manuscript preparation, Final proof. HK: Molecular analysis, Final proof. HSK: Study design, Molecular analysis, Data analysis, Manuscript preparation, Final proof.

\section{Funding}

This study was supported by Iran National Science Foundation (INSF) with grant number 97015174 and Faculty of Medicine, Tabriz University of Medical Sciences With grant number 59850

\section{Availability of data and materials}

All data and materials (DNA samples) are available by request from Author.

\section{Declarations}

Ethics approval and consent to participate

This Study was approved by local ethic committee with reference number IR.TBZMED.REC.1397.188. Only bacterial isolates were used in this study.

\section{Consent for publication}

All authors declare agreement and consent for publication.

\section{Competing interests}

The authors declare that they have no competing interests.

\section{Author details}

${ }^{1}$ Drug Applied Research Center, Tabriz University of Medical Sciences, Tabriz, Iran. ${ }^{2}$ Student Research Committee, Tabriz University of Medical Sciences, Tabriz, Iran. ${ }^{3}$ Immunology Research Center, Tabriz University of Medical Sciences, Tabriz, Iran. ${ }^{4}$ Division of Bacteriology, Department of Infection and Immunity, School of Medicine, Jichi Medical University, Shimotsuke, Tochigi, Japan.

Received: 22 January 2021 Accepted: 19 July 2021

Published online: 28 July 2021

\section{References}

1. Tannock GW, Cook G. Enterococci as members of the intestinal microflora of humans. In: The Enterococci. American Society of Microbiology; 2002. pp. 101-32.

2. Jett BD, Huycke MM, Gilmore MS. Virulence of enterococci. Clin Microbiol Rev. 1994;7(4):462-78. 
3. Willems RJ, Bonten MJ. Glycopeptide-resistant enterococci: deciphering virulence, resistance and epidemicity. Curr Opin Infect Dis. 2007;20(4):384-90.

4. Sedgley CM, Molander A, Flannagan SE, Nagel AC, Appelbe OK, Clewell DB, Dahlén G. Virulence, phenotype and genotype characteristics of endodontic Enterococcus spp. Oral Microbiol Immunol. 2005;20(1):10-9.

5. Rôças IN, Siqueira JF Jr, Santos KR. Association of Enterococcus faecalis with different forms of periradicular diseases. J Endod. 2004;30(5):315-20.

6. Hegstad K, Mikalsen T, Coque T, Werner G, Sundsfjord A. Mobile genetic elements and their contribution to the emergence of antimicrobial resistant Enterococcus faecalis and Enterococcus faecium. Clinical microbiology infection. 2010;16(6):541-54.

7. Arias CA, Contreras GA, Murray BE. Management of multidrug-resistant enterococcal infections. Clin Microbiol Infect. 2010;16(6):555-62.

8. Aarestrup FM, Agerso Y, Gerner-Smidt P, Madsen M, Jensen LB. Comparison of antimicrobial resistance phenotypes and resistance genes in Enterococcus faecalis and Enterococcus faecium from humans in the community, broilers, and pigs in Denmark. Diagn Microbiol Infect Dis. 2000;37(2):127-37.

9. Guerrero-Ramos E, Cordero J, Molina-González D, Poeta P, Igrejas G, Alonso-Calleja C, Capita R. Antimicrobial resistance and virulence genes in enterococci from wild game meat in Spain. Food microbiology. 2016;53:156-64.

10. Gholizadeh P, Aghazadeh M, Asgharzadeh M, Kafil HS. Suppressing the CRISPR/Cas adaptive immune system in bacterial infections. Eur J Clin Microbiol Infect Dis. 2017;36(11):2043-51.

11. Marraffini LA, Sontheimer EJ. CRISPR Interference Limits Horizontal Gene Transfer in Staphylococci by Targeting DNA. Science. 2008;322(5909):1843-5.

12. Palmer KL, Gilmore MS. Multidrug-resistant enterococci lack CRISPR-cas. MBio 2010; 1(4):e00227-00210.

13. Barrangou R, Fremaux C, Deveau H, Richards M, Boyaval P, Moineau S, Romero DA, Horvath P. CRISPR provides acquired resistance against viruses in prokaryotes. Science. 2007;315(5819):1709-12.

14. Gholizadeh P, Köse Ş, Dao S, Ganbarov K, Tanomand A, Dal T, Aghazadeh M, Ghotaslou R, Rezaee MA, Yousefi B, et al. How CRISPR-Cas system could be used to combat antimicrobial resistance. Infection Drug resistance. 2020;13:1111-21.

15. Brouns SJ, Jore MM, Lundgren M, Westra ER, Slijkhuis RJ, Snijders AP, Dickman MJ, Makarova KS, Koonin EV, Van Der Oost J. Small CRISPR RNAs guide antiviral defense in prokaryotes. Science. 2008;321(5891):960-4.

16. Makarova KS, Haft DH, Barrangou R, Brouns SJ, Charpentier E, Horvath P, Moineau S, Mojica FJ, Wolf YI, Yakunin AF. Evolution and classification of the CRISPR-Cas systems. Nat Rev Microbiol. 2011;9(6):467-77.

17. Bourgogne A, Garsin DA, Qin X, Singh KV, Sillanpaa J, Yerrapragada S, Ding Y, Dugan-Rocha S, Buhay C, Shen H. Large scale variation in Enterococcus faecalis illustrated by the genome analysis of strain OG1RF. Genome Biol. 2008;9(7):R110.

18. Haft DH, Selengut J, Mongodin EF, Nelson KE. A guild of 45 CRISPRassociated (Cas) protein families and multiple CRISPR/Cas subtypes exist in prokaryotic genomes. PLoS Comput Biol. 2005;1(6):e60.

19. Pourcel C, Salvignol G, Vergnaud G. CRISPR elements in Yersinia pestis acquire new repeats by preferential uptake of bacteriophage DNA, and provide additional tools for evolutionary studies. Microbiology. 2005;151(3):653-63.

20. Gomes BPFA, Pinheiro ET, Sousa ELR, Jacinto RC, Zaia AA, Ferraz CCR, de Souza-Filho FJ. Enterococcus faecalis in dental root canals detected by culture and by polymerase chain reaction analysis. Oral Surg Oral Med Oral Pathol Oral Radiol Endodontol. 2006;102(2):247-53.

21. Facklam R, Collins M. Identification of Enterococcus species isolated from human infections by a conventional test scheme. J Clin Microbiol. 1989;27(4):731-4.

22. Kafil HS, Mobarez AM, Moghadam MF, Hashemi ZS, Yousefi M. Gentamicin induces efaA expression and biofilm formation in Enterococcus faecalis. Microb Pathog. 2016;92:30-5.

23. Kariyama R, Mitsuhata R, Chow JW, Clewell DB, Kumon H. Simple and reliable multiplex PCR assay for surveillance isolates of vancomycin-resistant enterococci. J Clin Microbiol. 2000;38(8):3092-5.
24. Kafil HS, Mobarez AM, Moghadam MF. Adhesion and virulence factor properties of Enterococci isolated from clinical samples in Iran. Indian J Pathol Microbiol. 2013;56(3):238.

25. Clinical and Laboratory Standards Institute (CLSI). Performance Standards for Antimicrobial Susceptibility Testing. 27th ed. CLSI supplement M100. Wayne, PA: Clinical and Laboratory Standards Institute; 2017.

26. Rossetti L, Giraffa G. Rapid identification of dairy lactic acid bacteria by M13-generated, RAPD-PCR fingerprint databases. J Microbiol Methods. 2005:63(2):135-44.

27. Lindenstrauß AG, Pavlovic M, Bringmann A, Behr J, Ehrmann MA, Vogel RF. Comparison of genotypic and phenotypic cluster analyses of virulence determinants and possible role of CRISPR elements towards their incidence in Enterococcus faecalis and Enterococcus faecium. Syst Appl Microbiol. 2011;34(8):553-60.

28. Burley KM, Sedgley CM. CRISPR-Cas, a prokaryotic adaptive immune system, in endodontic, oral, and multidrug-resistant Hospital-acquired Enterococcus faecalis. J Endod. 2012;38(11):1511-5.

29. Lyons C, Raustad N, Bustos MA, Shiaris M. Incidence of Type II CRISPR1Cas systems in Enterococcus is species-dependent. PLOS ONE 2015, 10(11):e0143544

30. Borges AL, Davidson AR, Bondy-Denomy J. The discovery, mechanisms, and evolutionary impact of anti-CRISPRs. Ann Rev Virol. 2017;4:37-59.

31. Price VJ, McBride SW, Duerkop B, Palmer KL. CRISPR-Cas blocks antibiotic resistance plasmid transfer between Enterococcus faecalis strains in the gastrointestinal tract. bioRxiv 2018:312751.

32. Hullahalli K, Rodrigues M, Palmer KL. Exploiting CRISPR-Cas to manipulate Enterococcus faecalis populations. eLife. 2017;6:e26664.

33. Duerkop BA, Palmer KL, Horsburgh MJ. Enterococcal bacteriophages and genome defense. Massachusetts Eye and Ear Infirmary; 2014.

34. Horvath P, Coûté-Monvoisin A-C, Romero DA, Boyaval P, Fremaux C, Barrangou R. Comparative analysis of CRISPR loci in lactic acid bacteria genomes. Int J Food Microbiol. 2009;131(1):62-70.

35. Price VJ, Huo W, Sharifi A, Palmer KL. CRISPR-Cas and restriction-modification act additively against conjugative antibiotic resistance plasmid transfer in Enterococcus faecalis. Msphere. 2016;1(3):e00064-00016.

36. McBride SM, Fischetti VA, LeBlanc DJ, Moellering RC, Gilmore MS. Genetic diversity among Enterococcus faecalis. PLOS ONE 2007, 2(7):582

37. Palmer KL, Godfrey P, Griggs A, Kos VN, Zucker J, Desjardins C, Cerqueira G, Gevers D, Walker S, Wortman J, et al. Comparative Genomics of Enterococci: Variation in Enterococcus faecalis, Clade Structure in E. mBio. 2012;3(1):e00318-00311.

38. Palmer KL, Kos VN, Gilmore MS. Horizontal gene transfer and the genomics of enterococcal antibiotic resistance. Curr Opin Microbiol. 2010;13(5):632-9.

39. Lopardo HA, Vidal P, Jeric P, Centron D, Paganini H, Facklam RR, Elliott J. Six-month multicenter study on invasive infections due to group $B$ streptococci in Argentina. J Clin Microbiol. 2003;41(10):4688-94.

40. Martineau F, Picard FJ, Grenier L, Roy PH, Ouellette M, Bergeron MG. Multiplex PCR assays for the detection of clinically relevant antibiotic resistance genes in staphylococci isolated from patients infected after cardiac surgery. J Antimicrob Chemother. 2000;46(4):527-34.

41. Leelaporn A, Yodkamol K, Waywa D, Pattanachaiwit S. A novel structure of Tn4001-truncated element, type $V$, in clinical enterococcal isolates and multiplex PCR for detecting aminoglycoside resistance genes. Int J Antimicrob Agents. 2008;31(3):250-4

42. Clark NC, Olsvik $\varnothing$, Swenson JM, Spiegel CA, Tenover FC. Detection of a Streptomycin/Spectinomycin Adenylyltransferase Gene (aadA) in Enterococcus faecalis. Antimicrob Agents Chemother. 1999;43(1):157-60.

43. Van de Klundert J. PCR detection of genes coding for aminoglycosidemodifying enzymes. Diagn Mol Microbiol 1993:547-552.

44. Clark N, Cooksey R, Hill B, Swenson J, Tenover F. Characterization of glycopeptide-resistant enterococci from US hospitals. Antimicrob Agents Chemother. 1993;37(11):2311-7.

\section{Publisher's Note}

Springer Nature remains neutral with regard to jurisdictional claims in published maps and institutional affiliations. 